\title{
Chemotaxis and degradation of organophosphate compound by a novel moderately thermo-halo tolerant Pseudomonas sp. strain BUR11: evidence for possible existence of two pathways for degradation
}

Santanu Pailan, Pradipta Saha

An organophosphate (OP) degrading chemotactic bacterial strain BUR11 isolated from an agricultural field was identified as a member of Pseudomonas genus on the basis of its $16 \mathrm{~S}$ rRNA gene sequence. The strain could utilize parathion, chlorpyrifos and their major hydrolytic intermediates as sole source of carbon for its growth and exhibited positive chemotactic response towards most of them. Optimum concentration of parathion for its growth was recorded to be $200 \mathrm{ppm}$ and $62 \%$ of which was degraded within $96 \mathrm{~h}$ at $37^{\circ} \mathrm{C}$. Growth studies indicated the strain to be moderately thermo-halo tolerant in nature. Investigation based on identification of intermediates of parathion degradation by thin layer chromatography (TLC), high performance liquid chromatography (HPLC), gas chromatography (GC) and liquid chromatography mass spectrometry (LC-MS/MS) provided evidence for possible existence of two pathways. The first pathway proceeds via 4nitrophenol (4-NP) while the second proceeds through formation of 4-aminoparathion (4APar), 4-aminophenol (4-AP) and parabenzoquinone (PBQ). This is the first report of chemotaxis towards organophosphate compound by a thermo-halo tolerant bacterium. 
1 Chemotaxis and degradation of organophosphate compound by a novel moderately

2 thermo-halo tolerant Pseudomonas sp. strain BUR11: evidence for possible existence of two

3 pathways for degradation

4

5

6 Santanu Pailan and Pradipta Saha*

7 Department of Microbiology, the University of Burdwan, Golapbag, Burdwan-713104, West Bengal, India.

9 *Correspondence:

10 Email, psaha@microbio.buruniv.ac.in

11 Phone: +91-09433911957

12 Fax: +91-0342-2634015

13

14

15

16

17 


\section{Abstract}

22 An organophosphate (OP) degrading chemotactic bacterial strain BUR11 isolated from an 23 agricultural field was identified as a member of Pseudomonas genus on the basis of its $16 \mathrm{~S}$

24 rRNA gene sequence. The strain could utilize parathion, chlorpyrifos and their major hydrolytic 25 intermediates as sole source of carbon for its growth and exhibited positive chemotactic response towards most of them. Optimum concentration of parathion for its growth was recorded to be

$27200 \mathrm{ppm}$ and $62 \%$ of which was degraded within $96 \mathrm{~h}$ at $37^{\circ} \mathrm{C}$. Growth studies indicated the strain to be moderately thermo-halo tolerant in nature. Investigation based on identification of

29 intermediates of parathion degradation by thin layer chromatography (TLC), high performance liquid chromatography (HPLC), gas chromatography (GC) and liquid chromatography mass spectrometry (LC-MS/MS) provided evidence for possible existence of two pathways. The first pathway proceeds via 4-nitrophenol (4-NP) while the second proceeds through formation of 4aminoparathion (4-APar), 4-aminophenol (4-AP) and parabenzoquinone (PBQ). This is the first report of chemotaxis towards organophosphate compound by a thermo-halo tolerant bacterium. 
41 Organophosphate (OP) compounds are extensively used throughout the world as insecticides, 42 nematicide as well as chemical warfare agents (Kanekar, Bhadbhade \& Deshpande, 2004; Yang 43 et al., 2006). These compounds are toxic to human and other animals since they inhibit 44 acetylcholine esterase and are known to disrupt normal functions of central nervous system followed by severe muscle paralysis and death (Shen et al., 2010). Although banned in many countries, several of them, especially parathion and methyl parathion are still being used indiscriminately in India for controlling insect pests of major crops like paddy, potato, mustard, cotton and vegetables (Pakala et al., 2007; Banerjee et al., 2014). These toxic compounds and their hydrolysis products remain in soil, air, surface water as well as ground water long after their application in the field (KaviKarunya \& Reetha, 2012) and thus create health hazard. OP was first introduced as insecticide in the year 1947 and their half life varies (60 to 120 days for chlorpyrifos and 30 to 180 days for parathion) depending upon soil $\mathrm{pH}$, other abiotic and biotic factors (Singh \& Walker, 2006; Gao et al., 2012). Chlorpyrifos was reported to be degraded by Bacillus pumilus more efficiently $(80 \%)$ at basic and neutral $\mathrm{pH}$ compared to acidic $\mathrm{pH}$ (only 50\%) (Anwar et al., 2009). However, Chen et al. (Chen et al., 2012) reported more efficient degradation at acidic $\mathrm{pH}$ by a fungus, Cladosporium cladosporioides $\mathrm{Hu}-01$. OP compounds are acutely toxic to mammals, for example the $\mathrm{LD}_{50}$ of parathion for mammals is in the range 2-10 mg kg-1 (Singh \& Walker, 2006).

Reports in the literature suggest that several soil microorganisms, such as Flavobacterium sp. ATCC 27551 (Sethunathan \& Yoshida, 1973); Bacillus sp. and Pseudomonas sp. (Siddaramppa, Rajaram \& Sethunathan, 1973); Pseudomonas diminuta-MG (Serder et al., 1982; Mulbry et al., 1986); Pseudomonas putida KT2442 (Walker \& Keasling, 2002); Pseudomonas sp. (MinKyeong et al., 2009), Enterobacter strain B-14 (Singh et al., 2004), Alcaligens faecalis DSP3 
64 (Yang et al., 2005), Stenotrophomonas sp. strain YC-1 (Yang et al., 2006), Sphingomonas strain

65 Dsp-2 (Li, He \& Li, 2007), Paracoccus sp. strain TRP (Xu et al., 2008), B. pumilus strain C2A1

66 (Anwar et al., 2009) among bacteria and Verticillium sp. strain DSP (Fang et al., 2008),

67 Acremonium sp. strain GFRC-1 (Kulshrestha \& Kumari, 2011) and Cladosporium

68 cladosporioides Hu-01 (Chen et al., 2012)) among fungi are reported to be capable of degrading

69 OP-compounds either co-metabolically and in a very few cases catabolically. So far three

70 pathways by which parathion is degraded and the end products are channelized to TCA cycle

71 have been reported (Singh \& Walker, 2006). The most common pathway of parathion

72 degradation is through formation of 4-NP [which is further degraded through formation of either

73 4-nitrocatechol (4-NC) and or PBQ] while the second pathway is through paraoxon and 4-NP

74 and the third one is through formation of 4-APar and 4-AP (Munnecke \& Hsies, 1976). The third

75 pathway has been reported only for mixed bacterial culture and is believed to operate in limited

76 oxygen environment (Munnecke \& Hsies, 1976).

77 The first step in biodegradation is the bioavailability of a compound to the bacterial cells which

78 may be accomplished by chemotaxis. In order to biodegrade, bacteria must have access to the target compounds either by dissolution of the target compounds in the aqueous phase or by

80 adhesion of the bacteria directly to the non-aqueous phase liquid water interface. Survey of

81 literature revealed reports of many bacteria that showed chemotactic activity towards xenobiotic

82 compounds which have been postulated to be responsible for their efficient degradation (Pandey

83 \& Jain, 2002). However, extensive reports on positive chemotactic response towards OP

84 compounds and some of their degradation intermediates such as 4-AP and 3,5,6 trichloro-285 pyridinol (TCP) are lacking in literature. 
86 In this study we report for the first time positive chemotactic response of a novel, moderately

87 thermo-halo tolerant bacterium Pseudomonas sp. strain BUR11 towards OP compound and some

88 of their degradation intermediates such as 4-AP, TCP and 4-NP. We also demonstrate evidence

89 for possible existence of two pathways for degradation of parathion in this newly isolated

90 bacterial strain.

\section{Materials and Methods}

\section{Chemicals}

Parathion and its degradation intermediates [such as 4-NP, 4-AP, 4-NC, hydroquinone (HQ), PBQ and 1,2,4 benzenetriol (BT)] as well as TCP were purchased from Sigma. Chlorpyrifos was purchased from Dr. Ehrenstorfer GmbH (Merck, Germany). Solvents used in this study were of HPLC grade. Microbiological media, components, general chemicals were of highest standard and purchased from HiMedia, India.

\section{Isolation of OP degrading bacteria}

Soil samples were collected in sterile whirl pack bags (HiMedia, India) from an agricultural field in Burdwan (lat. 23.2500 $\mathrm{N}$ and long. $87.8500^{\circ} \mathrm{E}$ ), West Bengal, India. For isolation of parathion utilizing bacteria, an enrichment culture was set up in minimal medium (MM) $\left[\left(\mathrm{g} \mathrm{L}^{-1}\right)\right.$ : $\mathrm{K}_{2} \mathrm{HPO}_{4}, 0.2 ; \mathrm{KH}_{2} \mathrm{PO}_{4}, 0.8 ; \mathrm{MgSO}_{4} .7 \mathrm{H}_{2} \mathrm{O}, 0.2 ; \mathrm{CaSO}_{4} . \mathrm{H}_{2} \mathrm{O}, 0.1 ; \mathrm{NaMoO}_{4} .2 \mathrm{H}_{2} \mathrm{O}, 0.003 ;$ $\left.\mathrm{FeSO}_{4} .7 \mathrm{H}_{2} \mathrm{O}, 0.005 ;\left(\mathrm{NH}_{4}\right)_{2} \mathrm{SO}_{4}, 1.0\right]$ supplemented with $200 \mathrm{ppm}\left(\mathrm{mg} \mathrm{L}^{-1}\right)$ parathion. One gram of soil sample was added to the $25 \mathrm{~mL}$ of sterile $\mathrm{MM}$ (in a $100 \mathrm{~mL}$ Erlenmeyer flask) supplemented with filter sterilized parathion as the sole source of carbon and energy and was incubated in an orbital shaker $(120 \mathrm{rpm})$ at $37^{\circ} \mathrm{C}$ for 1 month. After 1 month, $1 \mathrm{~mL}$ of inoculum was transferred to $25 \mathrm{~mL}$ of fresh MM with $200 \mathrm{ppm}$ of parathion and incubated for 15 days and 
108 the process was repeated three more times. Dilution plating of this enrichment culture on MM

109 agar (1.5\% agar) plate supplemented with $200 \mathrm{ppm}$ of parathion and incubation at $37^{\circ} \mathrm{C}$ resulted

110 in many isolated colonies which were purified by restreaking on fresh medium. Based on growth

111 response on MM-parathion plate, one isolate designated BUR11 was selected for further studies.

\section{Characterization and identification of isolate BUR11}

113 Phenotypic characterization of strain BUR11 was carried out essentially according to Smibert \& 114 Krieg (1994). Growth at various temperatures $\left(20^{\circ} \mathrm{C}\right.$ to $\left.55^{\circ} \mathrm{C}\right)$ and $\mathrm{NaCl}$ concentrations was 115 determined by using basal tryptone soya broth with varying $\mathrm{NaCl}$ concentrations (0.5 to $8.5 \%)$, 116 followed by its periodic monitoring at $600 \mathrm{~nm}$ using a spectrophotometer. Strain BUR11 was 117 also identified by an automated microbial identification system, VITEK 2 (BioMérieux, Inc., 118 Hazelwood, MO, USA). Genomic DNA was isolated by Marmur's protocol (Johnson, 1994); 119 amplification of 16S rRNA gene and its sequencing was carried out according to Reddy et al., 120 (2000). Determination of phylogenetic neighbors and pair wise 16S rRNA gene sequence

121 identity was carried out at EzTaxon server (Chun et al., 2007). Phylogenetic tree was constructed 122 according to published methods (Saha \& Chakrabarti, 2006) with sequences of close 123 phylogenetic neighbors, retrieved from EzTaxon server.

\section{Growth studies and chemotactic behavior of strain BUR11}

125 Ability of the stain BUR11 to grow on parathion, chlorpyrifos, 4-NP, PBQ, HQ, 4-AP, TCP and 126 BT as sole sources of carbon was determined on MM broth supplemented with 200 ppm of the 127 compounds and incubation at $37^{\circ} \mathrm{C}$ with shaking at $120 \mathrm{rpm}$. Growth was monitored 128 spectrophotometrically (Varion, Cary $50 \mathrm{Bio}$ ) at $600 \mathrm{~nm}$, at regular time intervals. 
129 The chemotactic activity of the strain BUR11 towards parathion, chlorpyrifos, TCP, 4-NP and 4-

130 AP were investigated qualitatively (by drop plate and swarm plate assays) and quantitatively by

131 capillary assay following established methods (Pandey et al., 2002; Arora \& Bae, 2014). For

132 drop plate assay, culture was grown on MM supplemented with respective chemoattractants,

133 harvested $\left(\mathrm{OD}_{600} \sim 0.7\right)$ by centrifugation $(6000 \mathrm{~g}$ for $10 \mathrm{~min})$ washed twice with phosphate

134 buffered saline (PBS) and resuspended in assay medium (MM with $0.3 \%$ agarose), mixed well

135 and poured onto $60 \mathrm{~mm}$ Petri plates. The test compounds (either as crystals or as solution) were

136 placed in the centre of the plates which were then incubated at $37^{\circ} \mathrm{C}$. Swarm plate assay was

137 carried out on assay medium (MM with respective toxic compound plus $0.3 \%$ agarose) with 60

138 to $75 \mu \mathrm{L}$ of cells suspension in chemotaxis buffer, loaded centrally (in an agar cup that was cut

139 aseptically, using sterile cork borer), in a $60 \mathrm{~mm}$ Petri plate. Appearance of bacterial growth in

140 ring pattern (concentric rings in case of drop plate and exocentric in case of swarm plate assay)

141 were recorded as positive chemotactic response. For quantitative capillary assay, the optimum

142 concentration for each of the tested toxic compounds was determined by carrying out chemotaxis

143 assay at various concentrations (from 50 to $500 \mathrm{ppm}$ ). For the assay, $10 \mu \mathrm{L}$ graduated glass

144 capillary tubes were filled with parathion, chlorpyrifos, TCP, 4-NP and 4-AP (in chemotaxis

145 buffer) separately, and the suction end was sealed by sterile agarose gel. Each of these capillary

146 tubes was inserted into a micro centrifuge tube (separately) containing a suspension ( $10^{8}$ cells

$147 \mathrm{~mL}^{-1}$ ) of strain BUR11 cells and was incubated at $25^{\circ} \mathrm{C}$ for $30 \mathrm{~min}$. The contents of the capillary

148 tubes were then serially diluted and plated onto non-selective tryptone soya agar plate, followed

149 by determination of colony forming units (CFUs count) after overnight incubation at $37^{\circ} \mathrm{C}$. The

150 strength of chemotactic response was expressed in terms of the chemotaxis index (CI), which is

151 the ratio of the number of CFUs produced from the capillary containing the test compound(s) to 
152 CFUs produced from a control capillary (i.e. only the chemotaxis buffer without any chemo

153 tactic compound). Citrate was used as the positive control.

154 Inoculum preparation and extraction of samples for degradation studies

155 In order to carry out biodegradation studies, strain BUR11 was grown on tryptone soya broth for 156 overnight, cells were harvested by centrifugation, washed thrice with PBS ( $\mathrm{pH}-7.0)$ to remove

157 traces of medium and resuspended in $1.5 \mathrm{~mL}$ of MM. Cell suspension ( $0.5 \mathrm{OD}$ corresponding to $1586.5 \times 10^{7}$ cells $\left.\mathrm{mL}^{-1}\right)$ was inoculated into MM supplemented with parathion (200 ppm). Control 159 flask was prepared exactly the same way without inoculum and all flasks were incubated at $37^{\circ} \mathrm{C}$ 160 with shaking at $120 \mathrm{rpm}$. Entire broth culture was centrifuged and the supernatant was used for 161 extraction and amount of residual parathion in the medium was determined by HPLC after 0, 24, 16248,72 and $96 \mathrm{~h}$ of incubation.

For determination of hydrolysis products, after a periodic time interval of growth on MMparathion, cell free culture supernatant was collected and was subjected to extraction (twice) using equal volume of ethyl acetate, followed by dehydration using anhydrous sodium sulphate $\left(\mathrm{Na}_{2} \mathrm{SO}_{4}\right)$ and was dried by a rotary evaporator. The dried sample was dissolved in appropriate volume of acetonitrile, filtered through sterile disposable syringe filter (Millipore, $0.22 \mu \mathrm{m}$ ) and subjected to separation by TLC, LC-MS/MS and GC followed by library search for identification 169 of metabolites.

\section{Analytical methods}


172 Parathion and its degradation intermediates were quantified by HPLC using a HiQ sil C18

173 column (250 mm X 4.6 ID) and a Waters 515 HPLC equipped with a 486 tunable UV/Vis

174 detector. Parathion and intermediate metabolites were detected at $274 \mathrm{~nm}$ and acetonitrile: water

175 (80: 20) was used as the mobile phase at a flow rate of $1 \mathrm{~mL} \mathrm{~min}^{-1}$. Compounds were identified

176 by comparing their retention time to those of authentic standards. Quantitative aspects of

177 parathion and other intermediates were calculated from their standard curves (Shen et al., 2010;

178 Pailan et al., 2015).

179

180

181

182

183

184

185

186

187

188

189

190

191

192

193

194

\section{Identification of metabolites by TLC, HPLC, LC-MS/MS and GC}

For preliminary identification of hydrolytic intermediates during parathion hydrolysis, TLC was performed using precoated silica gel $60 \mathrm{~F}_{254}$ plates $(20$ x $20 \mathrm{~cm}$; Merck). $10 \mu \mathrm{L}$ of extracted sample was loaded on TLC Plate and was developed using n-hexane: acetone: ethyl acetate (80:10:10) solvent system. Visualization of TLC plate was carried out under UV light. HPLC was carried out as mentioned above and compounds were identified by comparing retention time of the test samples to that for authentic standards. LC-MS/MS was carried out using Sampler model no. G1329B for LC and MSQQQ Mass spectrometer for MS/MS (Agilent Technologies). The injection volume was $10 \mu \mathrm{L}$, solvent composition [methanol: ammonium formate (5 $\mathrm{mM})$ 90:10] was used as mobile phase with flow rate of $0.5 \mathrm{~mL} \mathrm{~min}^{-1}$ and stop time was $15 \mathrm{~min}$. MSMS was operated in following conditions, ion source was AJS-ESI, stop time was 25 min, gas temperature $325^{\circ} \mathrm{C}$, gas flow $6 \mathrm{~L} \mathrm{~min}^{-1}$ and capillary voltage were $4000 \mathrm{~V}$ and $3000 \mathrm{~V}$. GC (Agilent Technologies), equipped with PHENOMENEX_ZB_5_MS (30 m x $250 \mu \mathrm{m}$ x 0.25 $\mu \mathrm{m})$ column, was used for the separation of metabolites. Helium $(\mathrm{He})$ and Nitrogen $\left(\mathrm{N}_{2}\right)$ were used as quench gas and collision gas respectively with flow rate of $2.25 \mathrm{~mL} \mathrm{~min}^{-1}$ and $1.5 \mathrm{~mL}$ $\min ^{-1}$ respectively. The injection volume was $2 \mu \mathrm{L}$. The identification of intermediate 
195 compounds was carried out by comparing their mass spectrum profiles either to that of NIST

196 (NIST/EPA/NIH Mass spectral Library) library or to the same for standards.

197 Results

Isolation, characterization and identification of parathion degrading bacterium

199

200

201

202

203

204

205

206

207

208

209

210

211

212

215

213 Growth studies and chemotactic response of strain BUR11

214 Study of growth pattern revealed that the Pseudomonas sp. strain BUR11 could utilize parathion,

Several bacterial strains capable of utilizing parathion as sole source of carbon for their growth were isolated from soil of an agricultural field by enrichment culture technique. One of them designated as BUR11 showed comparatively good growth response in MM-parathion broth and MM-parathion-agar plate and was selected for further study.

The isolate BUR11 was Gram negative, rod-shaped, motile and possessed nitrate and nitrite reductase activities. The strain could grow between $20^{\circ} \mathrm{C}$ to $50^{\circ} \mathrm{C}$ temperatures and could tolerate up to $8 \% \mathrm{NaCl}$ (Fig. S1). Phenotypic characteristics of the strain are summarized in Table 1. The phylogenetic position of the strain is shown in Fig. 1. Although, it showed high value $(99.78 \%)$ of $16 \mathrm{~S}$ rDNA sequence similarity to the type strain of Pseudomonas aeruginosa $\left(\mathrm{JCM} 5962^{\mathrm{T}}\right)$, in absence of detail polyphasic taxonomic characterization, the strain BUR11 was identified as Pseudomonas sp. The strain has been deposited in Microbial Culture Collection, National Centre for Cell Science, Pune, India (accession number MCC 2328). Nucleotide sequence of the 16S rRNA gene for the strain BUR11 has been deposited in GenBank (accession number KF887018). chlorpyrifos (Fig. 2A) and their hydrolytic intermediates (such as 4-NP, 4-AP, HQ, PBQ, BT and 
216 TCP; Fig. 2B) as sole source of carbon. The strain could tolerate up to 500 ppm of parathion and

217 chlorpyrifos while its optimum growth was recorded at $200 \mathrm{ppm}$ for both the OP compounds.

218 The ability of this motile strain BUR11, to utilize OP compounds and their hydrolysis

219 intermediates prompted us to look for its chemotactic response towards these compounds.

220 Results from qualitative (Fig. S2A and Fig. S2B; drop plate and swarm plate assay respectively)

221 as well as quantitative (Fig. 3) chemotaxis assays indicated positive chemotaxis for five

222 compounds (parathion, 4-NP, 4-AP, chlorpyrifos and TCP) that were utilized as sole source of

223 carbon for growth by the strain BUR11. The capillary chemotaxis assay indicated concentration

224 dependent chemotaxis. As shown in Fig. 3, the CI values for all five compounds gradually

225 increased with increasing concentrations until the optimal concentrations. Further increase in

226 concentration led to sharp declines for chlorpyrifos, TCP and 4-AP while plateaus for parathion

227 and 4-NP in the strength of the chemotactic response. The optimal chemotactic response

228 concentrations were documented in the range between $200-250 \mathrm{ppm}$ for all the compounds used

229 as sole carbon source. The strongest chemotactic response was observed for chlorpyrifos and

230 TCP, with CI values of 30.1 and 28.5 respectively, at their respective optimal response

231 concentrations whereas CI of $16.25,18.83$ and 24.54 were recorded for parathion, 4-NP and 4-

232 AP. To, the best of our knowledge, this is the first report of chemotaxis towards chlorpyrifos,

233 parathion, 4-AP and TCP, by a moderately thermo-halo tolerant bacterium.

234 Degradation, hydrolytic intermediates and pathways for parathion degradation by BUR11

235 Study of the degradation of parathion by Pseudomonas sp. strain BUR11 revealed that the strain 236 could degrade $35 \%$ of parathion within $24 \mathrm{~h}$ and $62 \%$ of the same within $96 \mathrm{~h}$ as sole source of 237 carbon (Fig. 4A). As evident from Fig. 4B, within first 24 h, there was increase in concentration 238 of 4-NP, up to $30 \mathrm{ppm}$ and this does not change until $72 \mathrm{~h}$ after which its concentration 
239 decreased rapidly, indicating its mineralization. Other intermediates (HQ, PBQ and BT) were 240 detected in very low concentration, indicating their rapid conversion into intermediates which 241 were channelized finally into TCA cycle.

242 Preliminary analysis by TLC (Fig. S3), indicated presence of three metabolites namely, 4-NP, 243 PBQ, BT as major intermediates of hydrolysis. At least three more unidentified spots were 244 detected during TLC analysis. From comparative analyses (by HPLC) of retention time (RT) for 245 peaks of sample extracts and standards, HQ (RT of $2.258 \mathrm{~min}$ ); BT (RT of $2.195 \mathrm{~min}$ ), 4-NP (RT 246 of $2.440 \mathrm{~min}$ ) and PBQ (RT of $2.633 \mathrm{~min}$ ) were detected as major intermediates of hydrolysis of 247 parathion (Fig. S4). Separation of metabolites by GC followed by library search, detected and 248 identified 4-APar (RT $19.029 \mathrm{~min}$ ) in the parathion grown culture extract (Fig. S5). In LCMS/MS analysis, presence of characteristic mass spectra for 4-NP (ion, $m / z 137.9>108.0>$ 92.0), HQ (ion, $m / z 110>82.0>54.0>53.0$ ), PBQ (ion, $m / z 104.8$ ), 4-AP (ion, $m / z 104.9$ ), BT $(148.9>121.1>92.7)$ and 4-NC (ion, $m / z 148.9>92.7)$ were detected (Fig. S6).

LC-MS/MS analysis thus, confirmed the presence of six major hydrolysis intermediates, identified as 4-NP, HQ, PBQ, 4-NC, BT and 4-AP; while GC-screening predicted presence of 4APar. Since, both 4-NP (as well as 4-NC, BT, PBQ, HQ) and 4-APar (as well as 4-AP) were detected, we believe that in the strain BUR11, possibly, two pathways for degradation of parathion exists. Thus, based on detection of these intermediates we propose possible pathways of degradation of parathion for the strain BUR11 (Fig. 5). The proposed first pathway proceed via 4-NP that further degrades via two routes; one proceeds via 4-NC and BT whereas the other APar, 4-AP and PBQ (Fig. 5). 


\section{Discussion}

262 A parathion degrading bacterium, Pseudomonas sp. strain BUR11 was isolated from agricultural 263 soil by enrichment culture technique. The strain BUR11 not only utilized parathion but also 264 utilized its different hydrolytic intermediates like 4-NP, 4-AP, HQ, PBQ, BT as well as 265 chlorpyrifos and its major hydrolytic intermediate, TCP as sole source of carbon for its growth.

266 The strain could degrade $62 \%$ parathion within $96 \mathrm{~h}$ at $37^{\circ} \mathrm{C}$. Previously, Singh and Walker 267 (Singh \& Walker, 2006) has reported that OP utilization by different species of Pseudomonas as sole source of carbon but most of the authors have reported Pseudomonas aeruginosa as a member of a mixed bacterial culture for utilization of parathion (Munnecke \& Hsies, 1974; Pino, Dominuez \& Penuela, 2011). Degradation of parathion by reported bacterial strains proceeds through formation of 4-NP only and no bacterial strain has been reported where two different pathways are operative for degradation of parathion.

Evidence based on TLC, HPLC, GC and LC-MS/MS techniques indicated evidence for possible existence of two pathways for degradation of parathion by the strain BUR11. To the best of our knowledge this is the first report of a bacterium with two possible pathways for degradation of parathion. In the first pathway, the strain BUR11 converts parathion to 4-NP. The proposed second pathway of degradation of parathion in BUR11 proceeds through formation of 4-APar and 4-AP (Fig. 5). Till date, this second pathway is reported for a mixed bacterial culture that occurs under limited $\mathrm{O}_{2}$ condition (Munnecke \& Hsies, 1976). Sharmila et al. (Sharmila, Ramanand \& Sethunathan, 1989), reported a Bacillus sp. that could degrade methyl parathion,

281 through nitro group reduction, in the presence of yeast extract. This second pathway of 282 degradation of parathion involves reduction of nitro group to amine group, followed by 283 hydrolysis of ester bond to produce 4-AP. Reductive transformation of parathion and methyl 
284 parathion to 4-APar, under aerobic condition, catalyzed by oxygen insensitive nitroreductase 285 enzyme has been reported for Bacillus sp. (Yang et al., 2007). Similar light dependent aerobic 286 reduction has been reported earlier for Anabaena sp. PCC7120 (Barton et al., 2004). Although 287 not evaluated by enzyme assays, the strain BUR11, might possess similar $\mathrm{O}_{2}$ insensitive nitroreductase enzyme system to carry out conversion of parathion to 4-APar (i.e. nitro to amine group), to reduce toxicity, the ester bond is further hydrolyzed to release 4-AP, mineralized via PBQ and HQ. Moreover, the ability of the strain BUR11 to utilize all the intermediates (except 4-APar, which we could not test due to its unavailability) of this second pathway further strengthens the existence of enzyme system necessary for its utilization, in this bacterium. Currently, we do not understand how these two possible pathways operate in this bacterium and how these might be regulated.

To correlate a relationship between degradation and chemotaxis, we have also monitored the chemotactic behavior of Pseudomonas sp. strain BUR11 toward parathion, chlorpyrifos and their major degradation intermediates such as 4-NP, 4-AP and TCP using qualitative and quantitative chemotaxis assays. The strain BUR11 showed chemotaxis towards parathion, chlorpyrifos and their degraded intermediates products 4-NP, 4-AP as well as TCP. Although, genetic analysis are needed for better understanding of this chemotactic process, nevertheless, this feature is novel and unique to the best of our knowledge. Although, mineralization of chlorpyrifos and TCP was not addressed in this study, the capacity of the strain BUR11 to utilize them as sole source of carbon for growth strongly suggests that these compounds might also be mineralized. Thus, the strain BUR11 showed chemotaxis towards those compounds which it can metabolize (i.e. utilize and degrade chemo-attractants). However, we are not sure whether this chemotactic response is metabolism dependent or independent (Pandey \& Jain, 2002), as the chemotactic response of the 
307 BUR11 was not studied for those compounds which it cannot degrade or metabolize. Metabolism 308 dependent chemotaxis towards other toxic xenobiotic compounds has been reported for many 309 bacteria, such as Burkholderia sp. SJ98 towards various nitroaromatic compounds (Pandey et al., 310 2012), Pseudomonas sp. JHN towards 4-chloro, 2-NP (Arora \& Bae, 2014) and Ralstonia 311 eutropha towards 2, 4-dichlorophenoxyacetate (Hawkins \& Harwood, 2002). Unlike, these when 312 chemotaxis occurs independent of metabolism of chemo-attractants, it is called metabolism 313 independent chemotaxis as has been reported for Pseudomonas sp. WBC-3 and Pseudomonas 314 putida PRS2000, towards various aromatic compounds (Zhang et al., 2010; Parales, 2004; 315 Harwood \& Ornston, 1984; Harwood, Parales \& Dispensa, 1990). Chemotaxis offers a selective 316 advantage to degrading bacteria by guiding them to sense and locate toxic xenobiotic pollutants 317 that might be present in the environment. Chemotaxis towards toxic pollutants and their 318 mineralization indicate that chemotaxis might be an integral feature of degradation (Pandey \& 319 Jain, 2002; Marx \& Aitken, 2000) and its proper understanding might offer development of better bioremediation strategies for OP contaminated sites.

321 Genes for degradation of OP compounds are reported to be present in broad host range plasmids 322 such as pMCP424 and this has been shown to be disseminated among other soil dwelling 323 microorganism by transformation, conjugation and transduction (Horne et al., 2002; Bhadbhade 324 et al., 2002; Ochman, Lawrence \& Groisman, 2000; Springael \& Top, 2004). However, no 325 plasmids could be detected in strain BUR11. Moreover, plasmid curing treatments also did not 326 change the growth potential and vigor on OP compounds for the same strain, thereby indicating, 327 possibility of chromosome encoded genetic component to be involved in degradation.

328 Due to its indiscriminate, wide spread and persistent use, especially in India, OP insecticides are 329 a growing health issue that requires public attention and awareness. Although, several chemical 
330 and physical methods have been developed for removal of OP compounds (Theriot \& Grunden,

331 2011) from its contaminated sites, these are technically and economically challenging (Megharaj

332 et al., 2011). Bioremediation process involving living microorganisms or their enzymes has

333 recently received tremendous attention as eco-friendly, cost effective, safer approach to clean up

334 contaminated environments (Singh, 2009; Chen et al., 2011; Chen et al., 2012). Coordinated

335 studies carried out by addressing chemotaxis and degradation studies of toxic OP compounds

336 might develop better integrated approach towards bioremediation of these compounds. In most

337 cases, failure of bio-augmentation approaches is due to inability of the microorganisms to

338 tolerate biotic and abiotic stresses and application of microorganisms with better stress tolerance

339 capacity might improve these approaches (Tyagi, Fonseca \& Carvalho, 2011). In this regard,

340 chemotactic, thermo-halo tolerant bacterium, Pseudomonas sp. BUR11 with OP degradation

341 activity have better bioremediation capacity and might have immense biotechnological potential

342 for cost effective cleanup of OP contaminated sites.

\section{Conclusions}

344 Pseudomonas sp. BUR11 could degrade parathion using two pathways. First one through 345 formation of 4-NP while second pathway is through formation of 4-APar and 4-AP. The strain 346 also showed positive chemotaxis response towards OP compound, 4-NP, 4-AP and TCP. This is 347 the first report of chemotaxis towards OP compound by a thermo- halo tolerant bacterium.

\section{Acknowledgement(s):}

349 We are grateful to BUREAU VERITES, Chenni for GC and LC-MS/MS; Dr. W. Ghosh, 350 Microbiology Dept., and Mr. Swaroop Biswas, CIF, Bose Institute, Kolkata, for their help in 351 HPLC; Dr. Tapan Chakrabarti, MCC, NCCS, Pune for useful scientific discussions and 352 manuscript correction. 
353

354 355

356

357

358

359

360

361

362

363

364

365

366

367

368

369

370

371

372

373

\section{Conflict of interest statement:}

The authors declare that the research was conducted in the absence of any commercial or financial relationships that could be construed as a potential conflict of interest.

\section{Authors' contributions:}

Santanu Pailan performed all the experimental works. Pradipta Saha designed all experiment work prepared the manuscript, arranged fund from SERB, New Delhi. Both the authors read and approved the final manuscript.

\section{References}

Anwar S, Liaquat F, Khan QM, Khalid ZM, Iqbal S. 2009. Biodegradation of chlorpyrifos and its hydrolysis product 3,5,6-trichloro-2-pyridinol by Bacillus pumilus strain C2A1. Journal of Hazardous Materials 168:400-405 DOI 10.1016/j.jhazmat.2009.02.059.

Arora PK, Bae H. 2014. Biotransformation and chemotaxis of 4-chloro-2-nitrophenol by Pseudomonas sp. JHN. Microbial Cell Factories 13:110 DOI 10.1186/s12934-014$0110-7$

Banerjee I, Tripathi, SK, Roy AS, Sengupta P. 2014. Pesticide use pattern among farmers in a rural district of West Bengal, India. Journal of Natural Science, Biology and Medicine 5:313-316 DOI 10.4103/0976-9668.136173.

Barton JW, Kuritz T, O’Connor LE, Ma CY, Maskarinec MP, Davison BH. 2004. Reductive transformation of methyl parathion by the cyanobacterium Anabaena sp. strain PCC7120. Applied Microbiology and Biotechnology 65:330-335 DOI $10.1007 / \mathrm{s} 00253-004-1557-\mathrm{y}$. 
374 Bhadbhade BJ, Sarnaik SS, Kanekar PP. 2002. Biomineralization of an organophosphorus

375 pesticide, Monocrotophos, by soil bacteria. Journal of Applied Microbiology 93:2242346.

377 Chen S, Liu C, Peng C, Liu H, Hu M, Zhong G. 2012. Biodegradation of Chlorpyrifos and its hydrolysis product 3,5,6-trichloro-2-pyridinol by a new fungal strain Cladosporium cladosporioides Hu-01. PLoS ONE 7:e47205 DOI10.1371/journal.pone.0047205.

Chen SH, Hu MY, Liu JJ, Zhong GH, Yang L. 2011. Biodegradation of beta-cypermethrin and 3-phenoxybenzoic acid by a novel Ochrobactrum lupine DG-S-01. Journal of Hazardous Materials 187:433-440.

Chen SH, Luo JJ, Hu MY, Geng P, Zhang YB. 2012. Microbial detoxification of bifenthrin by a novel yeast and its potential for contaminated soils treatment. PLOS ONE 7:e30862.

Chun J, Lee J-H, Jung Y, Kim M, Kim S, Kim BK, Lim Y-W. 2007. EzTaxon: a web-based tool for the identification of prokaryotes based on 16S ribosomal RNA gene sequences. International Journal of Systematic and Evolutionary Microbiology 57:2259-2261 DOI 10.1099/ijs.0.64915-0.

Fang H, Xiang YQ, Hao YJ, Chu XQ, Pan XD. 2008. Fungal degradation of chlorpyrifos by Verticillium sp. DSP in pure cultures and its use in bioremediation of contaminated soil and pakchoi. International Biodeterioration and Biodegradation 16:294-303.

Gao Y, Chen S, Hu M, Hu Q, Luo J, Li Y. 2012. Purification and characterization of a novel chlorpyrifos hydrolase from Cladosporium cladosporioides Hu-01. PLoS ONE 6:e38137 DOI 10.1371/journal.pone.0038137.

Harwood CS, Ornston LN. 1984. TOL plasmid can prevent induction of chemotactic responses to aromatic acids. Journal of Bacteriology 160:797-800. 
397 Harwood CS, Parales RE, Dispensa M. 1990. Chemotaxis of Pseudomonas putida toward 398 chlorinated benzoates. Applied and Environmental Microbiology 56:1501-1503.

399

400

401

402

403

404

405

406

407

Hawkins AC, Harwood CS. 2002. Chemotaxis of Ralstonia eutropha JMP134 (pJP4) to the herbicide 2, 4-dichlorophenoxyacetate. Applied and Environmental Microbiology 68:968-972 DOI 10.1128/AEM.68.2.968-972.2002.

Horne I, Tara D, Sutherland R, Harcourt L, Russell RJ, Oakeshott JG. 2002. Identification of an opd (organophosphate degradation) gene in an Agrobacterium isolate. Applied and Environmental Microbiology 68:3371-3376.

Johnson JL. 1994. Similarity analysis of rRNA. In: Gerhard P, Murray RGE, Wood WA, Krieg NR. eds. Methods for general and molecular bacteriology. Washington, D.C.: ASM, 683-700.

Kanekar PP, Bhadbhade BJ, Deshpande NM. 2004. Biodegradation of Organophosphate Pesticides. Proceedings of Indian National Sciences Academy B70:57-70.

KaviKarunya S, Reetha D. 2012. Biological degradation of chlorpyrifos and monocrotophos by bacterial isolates. International Journal of Pharmaceutical and Biological Archives 3:685-691.

Kulshrestha G, Kumari A. 2011. Fungal degradation of chlorpyrifos by Acremonium sp. strain (GFRC-1) isolated from a laboratory-enriched red agricultural soil. Biology and Fertility of Soils 47:219-225.

Li XH, He J, Li SP. 2007. Isolation of a chlorpyrifos-degrading bacterium, Sphingomonas sp. strain Dsp-2, and cloning of the mpd gene. Research in Microbiology 158:143-149. 
418 Marx RB, Aitken MD. 2000. Bacterial chemotaxis enhances naphthalene degradation in a heterogenous aqueous system. Environmental Science and Technology 34:3379-3383 DOI 10.1021/es000904k CCC: \$19.00.

421

422

423

424

425

426

427

428

429

430

431

432

433

434

435

436

437

438

439

Megharaj M, Ramakrishnan B, Venkateswarlu K, Sethunathan N, Naidu R. 2011. Bioremediation approaches for organic pollutants: A critical perspective. Environment International 37:1362-1375.

Min-Kyeong C, Kim K-D, Ahn K-M, Shin D-H, Hwang J-H, Seong CN, Ka J-O. 2009. Genetic and phenotypic diversity of parathion-degrading bacteria isolated from rice paddy soils. Journal of Microbiology and Biotechnology 19:1679-1687 DOI 10.4014/jmb.0905.05057.

Mulbry WW, Karns JS, Kearney PC, Nelson JO, Wild JR. 1986. Identification of a plasmid-borne parathion hydrolase gene from Flavobacterium sp. by southern hybridization with opd from Pseudomonas diminuta. Applied and Environmental Microbiology 51:926-930.

Munnecke DM, Hsies DPH. 1974. Microbial decontamination of parathion and $p$ nitrophenol in aqueous media. Applied Microbiology 28:212-217.

Munnecke DM, Hsies DPH. 1976. Pathways of microbial metabolism of parathion. Applied and Environmental Microbiology 31:63-69.

Ochman H, Lawrence JG, Groisman EA. 2000. Lateral gene transfer and the nature of bacterial innovation. Nature 405:299-304.

Pailan S, Gupta D, Apte S, Krishnamurthi S, Saha P. 2015. Degradation of organophosphate insecticide by a novel Bacillus aryabhattai strain SanPS1, isolated 
440

441

442

443

444

445

446

447

448

449

from soil of agricultural field in Burdwan, West Bengal, India. International Biodeterioration Biodegradation 103:191-195. DOI 10.1016/j.ibiod.2015.05.006.

Pakala SB, Gorla P, Pinjari AB, Krovidi RK, Baru R, Yanamandra M, Merrick M, Siddavattam D. 2007. Biodegradation of methyl parathion and $p$-nitrophenol: evidence for the presence of a p-nitrophenol 2-hydroxylase in a Gram-negative Serratia sp. strain DS001. Appllied Microbiology and Biotechnology 73:1452-1462 DOI 10.1007/s00253006-0595-z.

Pandey G, Chauhan A, Samanta SK, Jain RK. 2002. Chemotaxis of a Ralstonia sp. SJ98 toward co-metabolizable nitroaromatic compounds. Biochemical and Biophysical Research Communication 299:404-409 DOI 10.1016/S0006-291X (02)02601-3.

Pandey G, Jain RK. 2002. Bacterial chemotaxis toward environmental pollutants: role in bioremediation. Applied and Environmental Microbiology 68:5789-5795 DOI 10.1128/AEM.68.12.5789-5795.2002.

Pandey J, Sharma NK, Khan F, Ghosh A, Oakeshott JG, Jain RK, Pandey G. 2012. Chemotaxis of Burkholderia sp. strain SJ98 towards chloronitroaromatic compounds that it can metabolize. BMC Microbiology 1:19 DOI 10.1186/1471-2180-12-19.

Parales RE. 2004. Nitrobenzoates and aminobenzoates are chemoattractants for Pseudomonas strains. Applied and Environmental Microbiology 70:285-292 DOI 10.1128/AEM.70.1.285-292.2004.

Pino NJ, Dominguez MC, Penuela GA. 2011. Isolation of a selected microbial consortium capable of degrading methyl parathion and $p$-nitrophenol from a contaminated soil site. Journal of Environmental Science and Health 46:173-180 DOI 10.1080/03601234.2011.539142. 
463 Reddy GSN, Aggarwal RK, Matsumoto GI, Shivaji S. 2000. Arthobacter flavus sp. nov., a 464 psychrophilic bacterium isolated from a pond in McMurdo dry valley, Antarctica. International Journal of Systematic and Evolutionary Microbiology 50:1553-1561.

466

467

468

469

470

471

472

473

474

475

476

477

478

479

480

481

482

483

484

485

Saha P, Chakrabarti T. 2006. Emticicia oligotrophica gen nov., a new member of the family' Flexibacteraceae', phylum Bacteroidetes. International Journal of Systematic and Evolutionary Microbiology 56:991-995 DOI 10.1099/ijs.0.64086-0.

Serdar CM, Gibson DT, Munnecke DM, Lancaster JH 1982. Plasmid involvement in parathion hydrolysis by Pseudomonas diminuta. Applied and Environmental Microbiology 44:246-249.

Sethunathan N, Yoshida T. 1973. A Flavobacterium sp. that degrades diazinon and parathion. Canadian Journal of Microbiology 19:873-875 DOI 10.1139/m73-138.

Sharmila M, Ramanand K, Sethunathan N. 1989. Effect of yeast extract on the degradation of Organophosphorus insecticides by soil enrichment and bacterial cultures. Canadian Journal of Microbiology 35:1105-1110 DOI 10.1139/m89-185.

Shen Y-J, Lu P, Mei H, Yu H-J, Hong Q, Li S-P. 2010. Isolation of a methyl parathiondegrading strain Stenotrophomonas sp. SMSP-1 and cloning of the ophc2 gene. Biodegradation 21:785-792 DOI 10.1007/s10532-010-9343-2.

Siddaramppa R, Rajaram KP, Sethunathan N. 1973. Degradation of Parathion by bacteria isolated from flooded soil. Applied Microbiology 26:846-849.

Singh BK. 2009. Organophosphate degrading bacteria, ecology and industrial application. Nature Reviews 7:156-164.

Singh BK, Walker A. 2006. Microbial degradation of organophosphorous compounds. FEMS Microbiology Reviews 30:428-471 DOI 10.1111/j.1574-6976.2006.00018.x. 
486 Singh BK, Walker A, Morgan JAW, Wright DJ. 2004. Biodegradation of Chlorpyrifos by

487

488

489

490

491

492

493

494

495

496

497

498

499

500

501

502

503

504

505

506

507

508

Enterobacter strain B-14 and its use in the bioremediation of contaminated soils. Applied and Environmental Microbiology 70:4855-4863.

Smibert RM, Krieg NR. 1994. Phenotypic characterization. In: Gerhard P, Murray RGE, Wood WA, Krieg NR, eds. Methods for general and molecular bacteriology. Washington, D.C.: ASM, 607- 654.

Springael D, Top EM. 2004. Horizontal gene transfer and microbial adaptation to xenobiotics: new types of mobile genetic elements and lesion from ecological studies. Trends Microbiology 12:53-58.

Theriot CM, Grunden AM. 2011. Hydrolysis of organophosphorus compounds by microbial enzymes. Applied Microbiology and Biotechnology 89:35-43.

Tyagi M, Fonseca da MMR, Carvalho de CCCR. 2011. Bioaugmentation and bio-stimulation strategies to improve the effectiveness of bioremediation processes. Biodegradation $22: 231-241$.

Walker AW, Keasling JD. 2002. Metabolic engineering of Pseudomonas putida for the utilization of parathion as a carbon and energy source. Biotechnology and Bioengineering 78:715-721 DOI 10.1002/bit.10251.

Xu GM, Zheng W, Li YY, Wang SH, Zhang JS. 2008. Biodegradation of chlorpyrifos and 3,5,6-trichloro-2-pyridinol by a newly isolated Paracoccus sp. TRP. International Biodeterioration and Biodegradation 62: 51-56.

Yang C, Dong M, Yuan Y, Huang Y, Guo X, Qiao C. 2007. Reductive transformation of parathion and methyl parathion by Bacillus sp. Biotechnology Letters 29:487-493 DOI 10.1007/s10529-006-9264-7. 
509 Yang C, Liu N, Guo X, Qiao C. 2006. Cloning of mpd gene from a chlorpyrifos-degrading 510 bacterium and use of this strain in bioremediation of contaminated soil. FEMS Microbiology Letters 265:118-125 DOI 10.1111/j.1574-6968.2006.00478.x.

512 Yang L, Zhao YH, Zhang BX, Yang CH, Zhang X. 2005. Isolation and characterization of a chlorpyrifos and 3,5,6-trichloro-pyridinol degrading bacterium. FEMS Microbiology Letters 251: 67-73.

Zhang J, Xin Y, Liu H, Wang S, Zhou N. 2010. Metabolism-independent chemotaxis of Pseudomonas sp. strain WBC-3 toward aromatic compounds. Journal of Environmental Science 20:1238-1242.

Table Legends

Table 1 Phenotypic characteristics of the strain Pseudomonas sp. BUR11. 


\section{Figure Legends}

545 Figure 1 Phylogenetic relationship between strain BUR11 and other closely related species of 546 the genus Pseudomonas based on 16S rRNA gene sequences. The tree was generated by

547 Neighbour-Joining method using TREECON software. Bootstrap values (as real value of 100 548 replications) are shown at the nodes. Bar, 0.05 base substitutions per site. Sequence from 549 Rhizobacter dauci was used as an out-group.

550 Figure 2 Growth profile of strain BUR11 on (A) different OP compounds (as sole carbon 551 source; 200 ppm), (B) On different hydrolysis intermediates of OP compounds (4-NP, HQ, PBQ, 552 BT, 4-AP and TCP), citrate $(0.5 \%)$ and on tryptone soya broth $(3 \%)$.

553 Figure 3 Quantitation of the chemotactic response and determination of optimal response 554 concentration for BUR11 chemotaxis towards different test compounds using capillary assays. 
555 Figure 4 (A) Parathion degradation profile by the strain BUR11 and (B) Fate of intermediates

556 during parathion degradation by the strain BUR11.

557 Figure 5 Proposed pathway for the degradation of parathion by the strain BUR11.

558

559

560

561

562

563

\section{Supplemental Figure}

564 Figure S1 Comparative growth profile of BUR11 on increasing concentration of $\mathrm{NaCl}$.

565 Figure S2 Qualitative chemotactic response of BUR11 towards parathion, chlorpyrifos, 4-NP, 4-

566 AP and TCP. (A) Drop plate assay and (B) Swarm plate assay.

567 Figure S3 Identification of metabolites of parathion degradation by TLC. Authentic standards 1,

568 parathion; 2, 4-NP; 3, PBQ; 4, HQ; 5, 4-NC; 6, BT; 7, 4-AP. While, 8 and 9 correspond to $72 \mathrm{~h}$

569 and $120 \mathrm{~h}$ extract of parathion grown culture, indicating the detection of 4-NP, PBQ and BT

570 during course of degradation.

571 Figure S4 Parathion degradation by strain BUR11. The elution profile of each sample is shown

572 as individual HPLC chromatograms. $0 \mathrm{~h}$ test sample (A), $24 \mathrm{~h}$ test sample (B) and $96 \mathrm{~h}$ test

573 sample (C) and elution profile of standards [D, Parathion; E, 4-NP; F, PBQ; G, HQ; H, 4-NC and 574 I, BT]. 
575 Figure S5 GC spectra of parathion grown culture. The peak having RT of 19.030 min was 576 identified as 4-APar by NIST library search.

577 Figure S6 LC-MS/MS spectra of major intermediates of parathion degradation by strain BUR11.

578 A, 4-NP; B, HQ; C, 4-AP; D, PBQ; E, 4-NC and F, BT. Metabolites were identified and 579 confirmed based on matches from NIST library search. 


\section{Table $\mathbf{1}$ (on next page)}

Phenotypic characters

Phenotypic characteristics of the strain Pseudomonas sp. BUR11. 
1

2 Table 1 Phenotypic characteristics of the strain Pseudomonas sp. BUR11.

3

4

\begin{tabular}{|l|l|}
\hline Test & Results \\
\hline $\begin{array}{l}\text { Caseinase, Catalase, Oxidase, Phosphatase } \\
\text { activity }\end{array}$ & + \\
\hline $\mathrm{NaCl}$ tolerance & Up to $8 \%$ \\
\hline Growth temperature & $20^{\circ} \mathrm{C}$ to $50^{\circ} \mathrm{C},\left(37^{\circ} \mathrm{C}\right.$ optimum $)$ \\
\hline Hydrolysis of & + \\
\hline $\begin{array}{l}\text { Esculin, Gelatin } \\
\text { L-Arabinose, Citrate, Galactose, Glucose, } \\
\text { Malonate, D-Mannose, Xylitol, Xylose, }\end{array}$ & \\
\hline
\end{tabular}

5 (+, positive reaction), * Data taken from GN card of VITEK 2 System Version: 06.01 6

7 


\section{1}

Phylogenetic tree

Phylogenetic relationship between strain BUR11 and other closely related species of the genus Pseudomonas based on 16S rRNA gene sequences. The tree was generated by Neighbour-Joining method using TREECON software. Bootstrap values (as real value of 100 replications) are shown at the nodes. Bar, 0.05 base substitutions per site. Sequence from Rhizobacter dauci was used as an out-group.

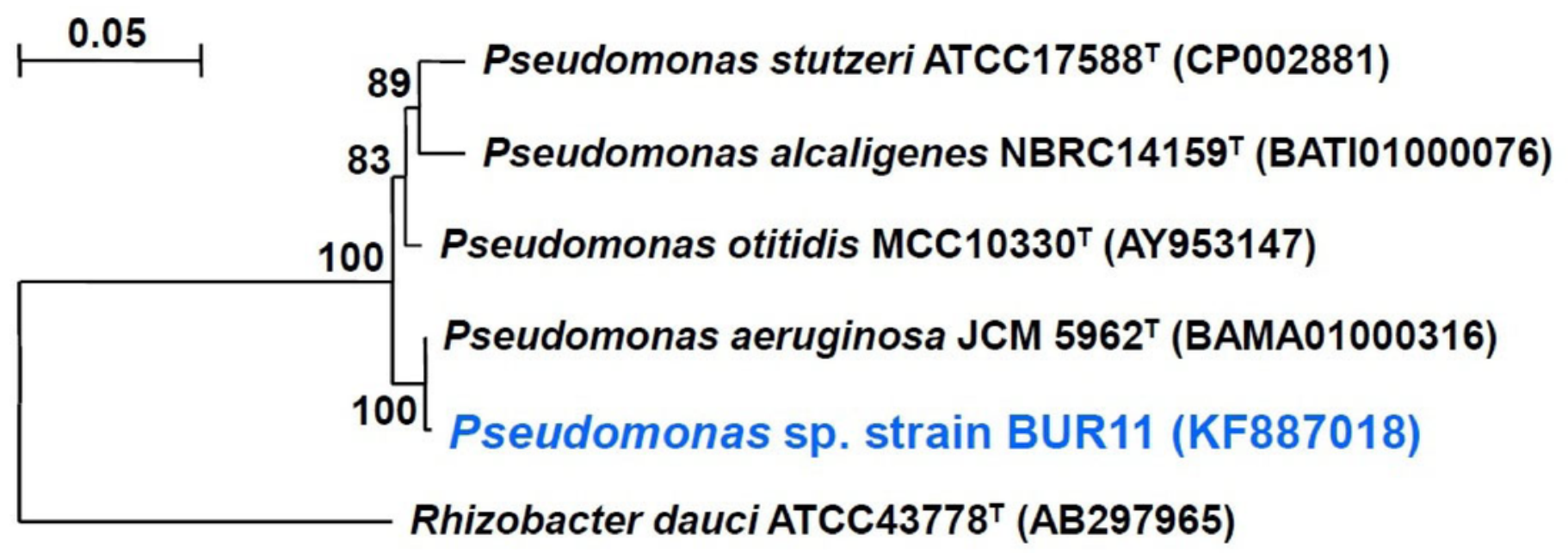


2

Growth of BUR11 in presence of OP compounds and their hydrolytic intermediates

Growth profile of strain BUR11 on (A) different OP compounds (as sole carbon source; 200 ppm), (B) On different hydrolysis intermediates of OP compounds (4-NP, HQ, PBQ, BT, 4-AP and TCP), citrate (0.5\%) and on tryptone soya broth (3\%).
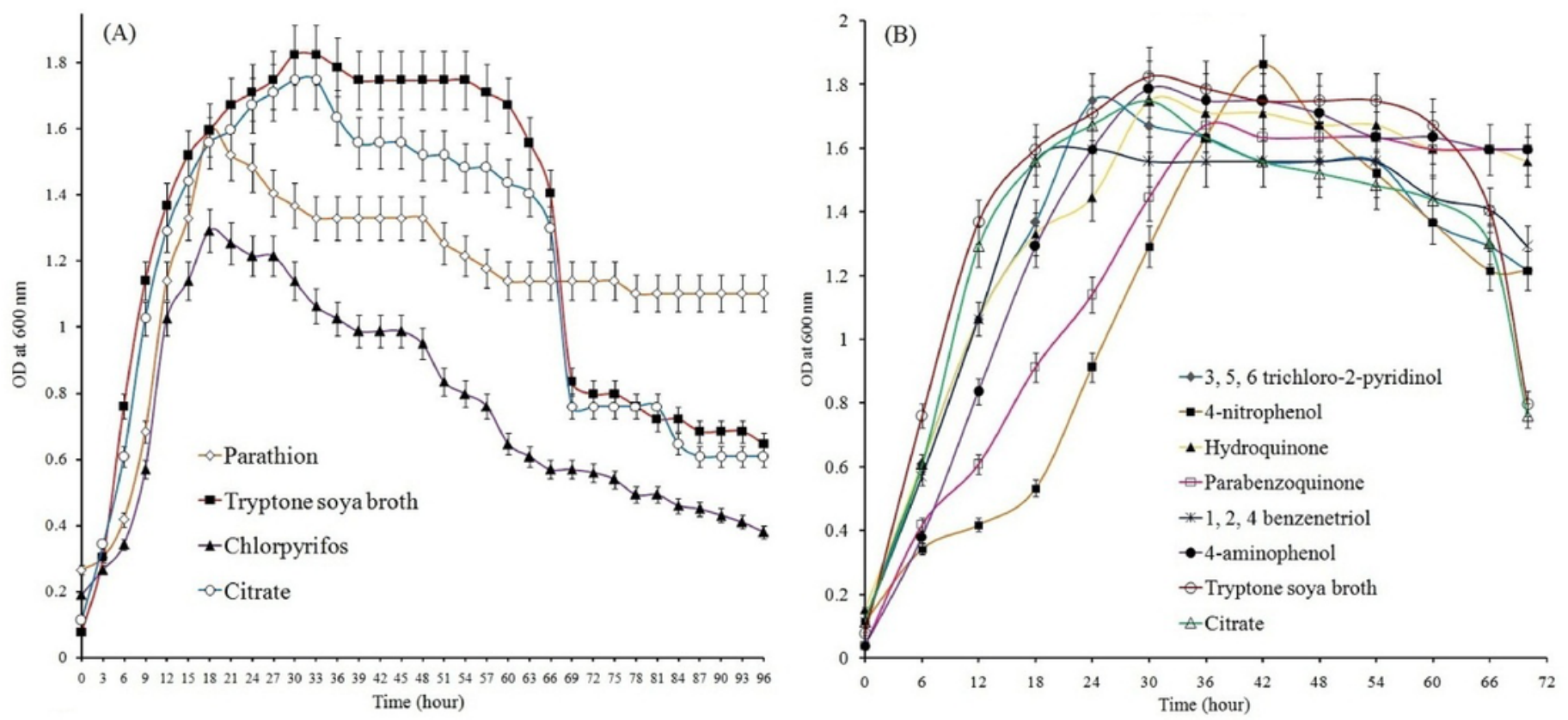
3

Quantitative capillary assay

Quantitation of the chemotactic response and determination of optimal response concentration for BUR11 chemotaxis towards different test compounds using capillary assays. 


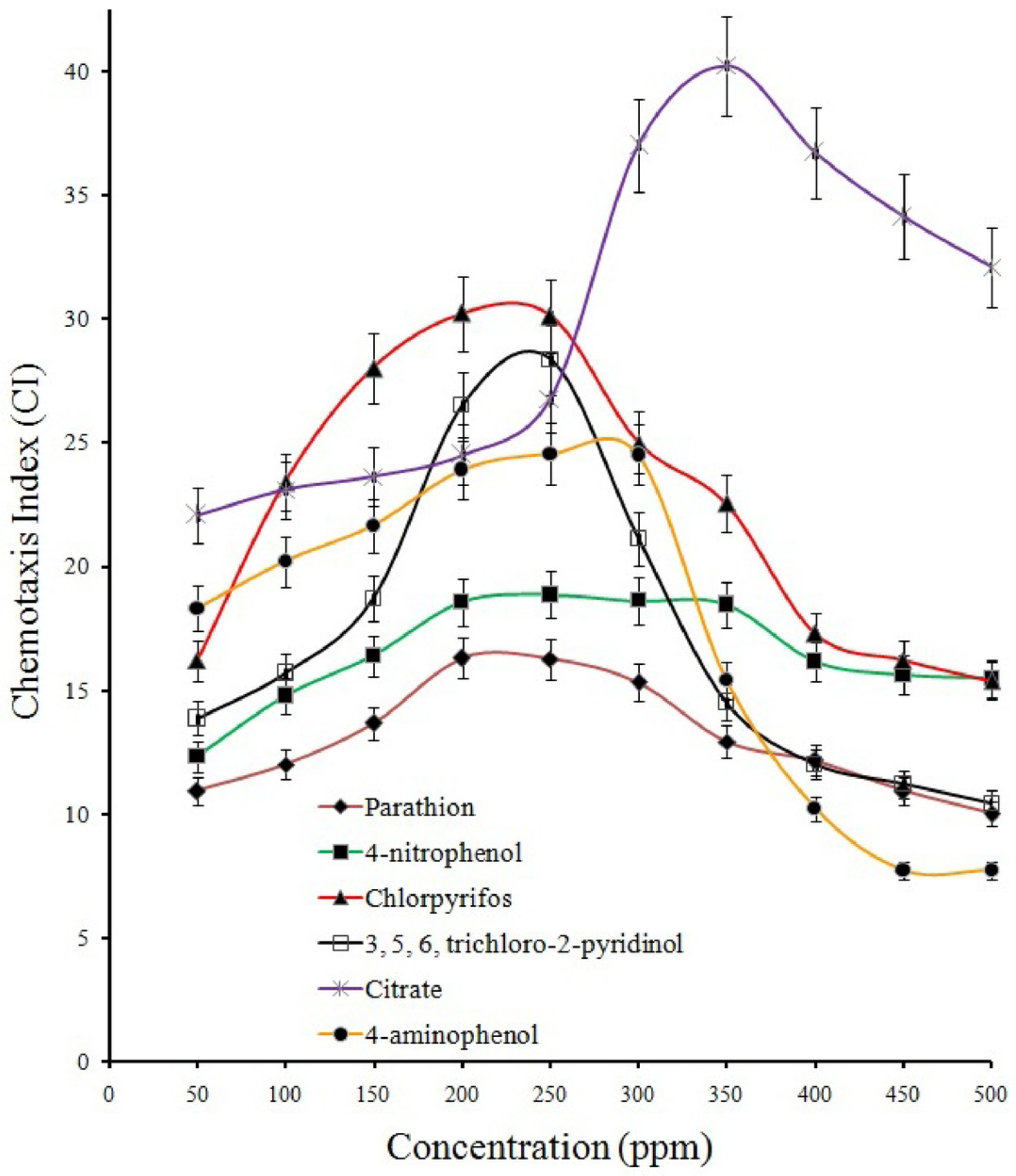


4

Parathion degradation profile of BUR11

(A) Parathion degradation profile by the strain BUR11 and (B) Fate of intermediates during parathion degradation by the strain BUR11.
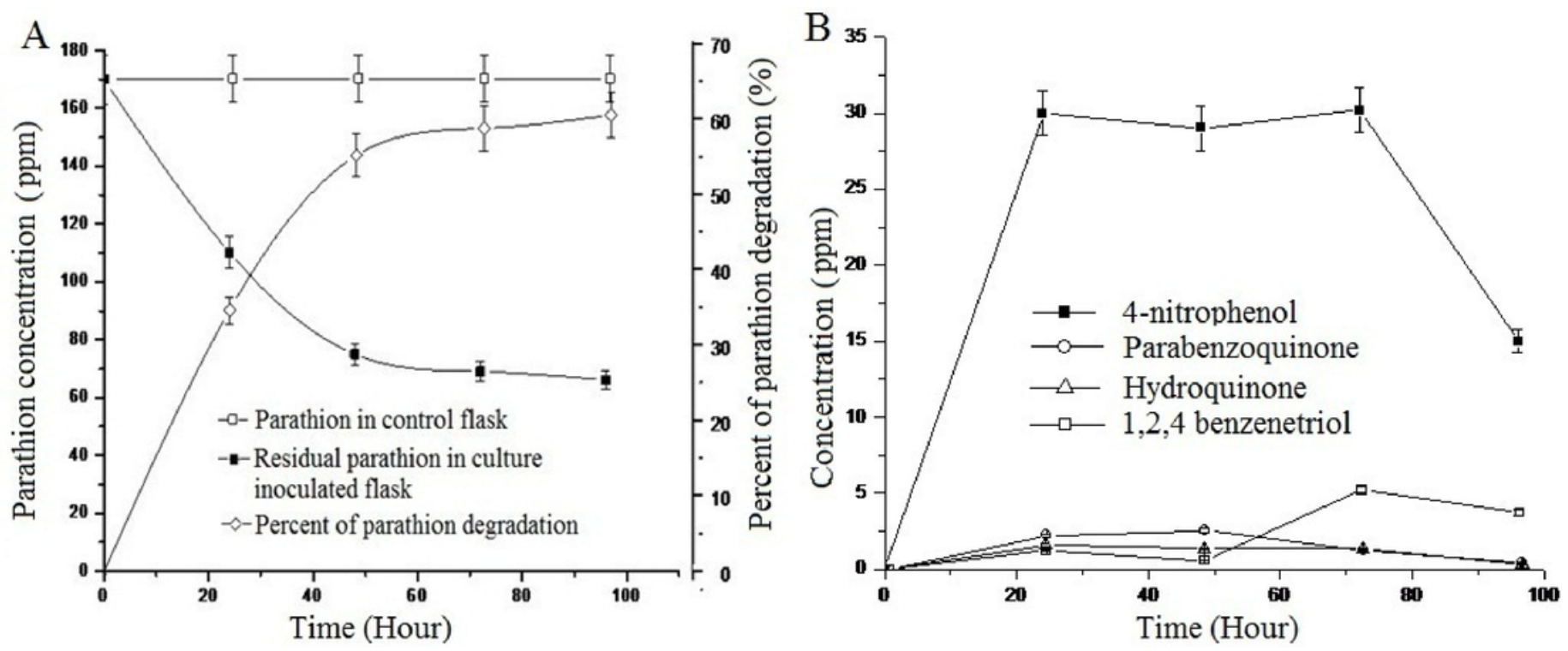
5

Parathion degradation pathway

Proposed pathway for the degradation of parathion by the strain BUR11.

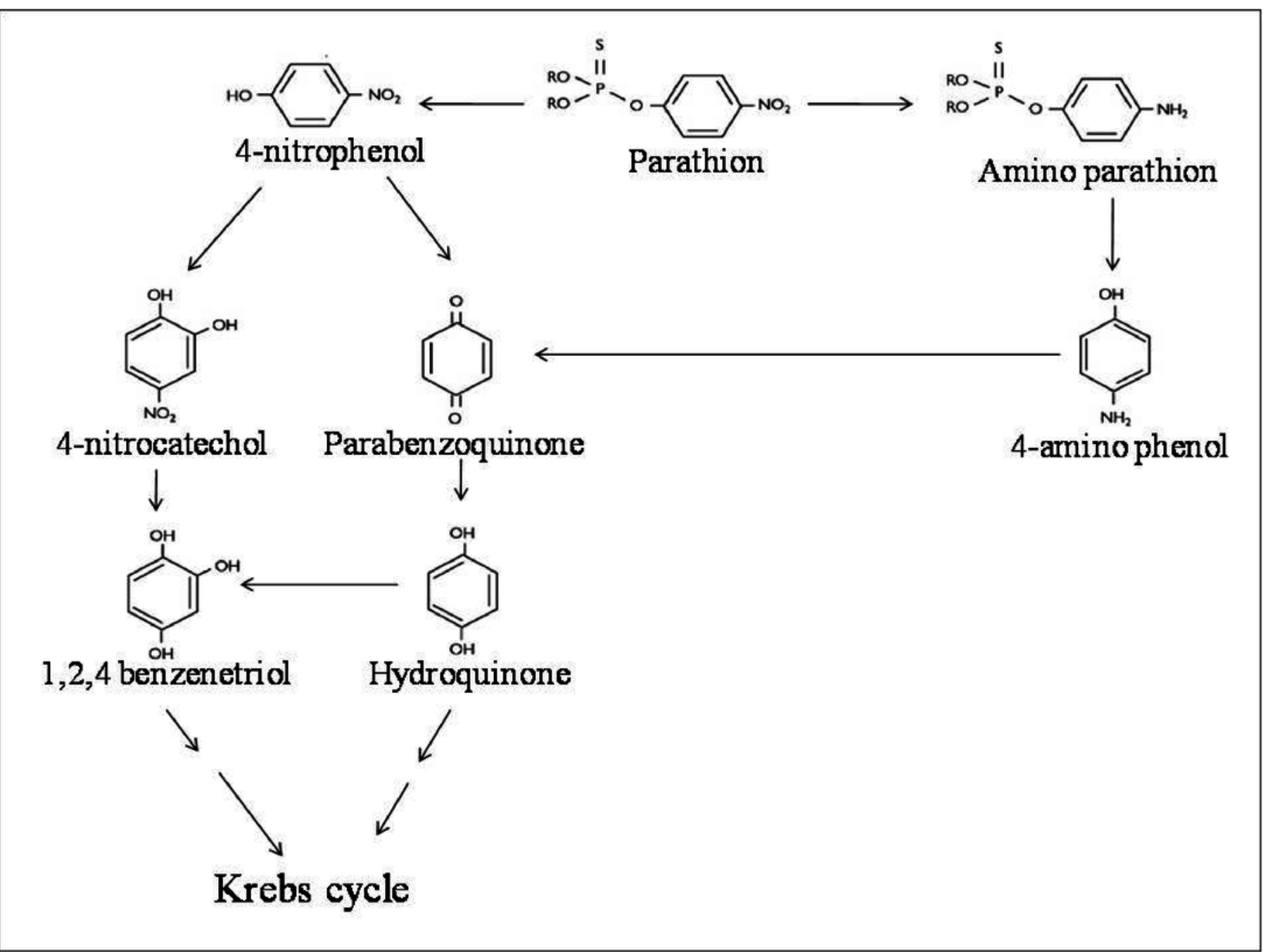

